\title{
Effect of surface conditioning methods, adhesive systems and resin composite on repair strength of dimethacrylate and silorane resin composites
}

Lima, Adriano Fonseca ; de Vicente Leiteb, Thatiana ; Palialol, Alan Muniz ; Catelan, Anderson ; Aguiar, Flávio Henrique Baggio ; Marchi, Giselle Maria ; Yuzbasioglu, Emir ; Ȯzcan, Mutlu

DOI: https://doi.org/10.1080/01694243.2016.1199217

Posted at the Zurich Open Repository and Archive, University of Zurich

ZORA URL: https://doi.org/10.5167/uzh-128021

Journal Article

Accepted Version

Originally published at:

Lima, Adriano Fonseca; de Vicente Leiteb, Thatiana; Palialol, Alan Muniz; Catelan, Anderson; Aguiar, Flávio Henrique Baggio; Marchi, Giselle Maria; Yuzbasioglu, Emir; Özcan, Mutlu (2016). Effect of surface conditioning methods, adhesive systems and resin composite on repair strength of dimethacrylate and silorane resin composites. Journal of Adhesion Science and Technology, 30(24):2736-2744.

DOI: https://doi.org/10.1080/01694243.2016.1199217 
Effect of surface conditioning methods, adhesive systems and resin composite on repair strength of dimethacrylate and silorane resin composites

Adriano Fonseca Lima, DDS, MS, $\mathrm{PhD}^{\mathrm{a}}$ / Thatiana de Vicente Leite, DDS, MS ${ }^{\mathrm{b}}$ I Alan Muniz Palialol, DDS, MS $^{\mathrm{b}}$ / Anderson Catelan, DDS, MS, $\mathrm{PhD}^{\mathrm{b}}$ / Flávio Henrique Baggio Aguiar, DDS, MS, $\mathrm{PhD}^{\mathrm{b}} /$ Giselle Maria Marchi, DDS, MS, $\mathrm{PhD}^{\mathrm{b}}$ / Emir Yuzbasioglu, DDS, $\mathrm{PhD}^{\mathrm{c}, \mathrm{d}}$ / Mutlu Özcan, DDS, Dr.med.dent., PhD

${ }^{a}$ Dental Research Division, School of Dentistry, Paulista University, São Paulo, Brazil ${ }^{b}$ Piracicaba Dental School, State University of Campinas, Piracicaba, Brazil

${ }^{c}$ Department of Prosthodontics, School of Dentistry, Istanbul Medipol University, İstanbul, Turkey

${ }^{d}$ Biomaterials and Translational Dental Research Laboratory, Center for Regenerative and Restorative Medical Research (REMER), Istanbul, Turkey

${ }^{e}$ University of Zurich, Dental Materials Unit, Center for Dental and Oral Medicine, Clinic for Fixed and Removable Prosthodontics and Dental Materials Science, Zurich, Switzerland

Short title: Surface conditioning methods on repair of silorane

Correspondance to: Dr. Emir Yuzbasioglu, DDS, PhD. Istanbul Medipol University, School of Dentistry, Department of Prosthodontics, Ataturk Bulvarı, No:27, 34083, Fatih-Istanbul, Turkey, Tel: +90 21245349 53, Fax: +90 21253175 55. e-mail: emiryuzbasioglu@hotmail.com 
Abstract: This study evaluated the effect of surface conditioning methods and adhesive systems on the repair bond strength of resin composites. Specimens (FLS: Filtek LS) $(\mathrm{N}=144)$ were prepared using a silicone matrix. The specimens were stored in distilled water and then were randomly divided into the twelve groups $(n=12)$ according to the surface conditioning method (unground or diamond bur) and adhesive system (no adhesive, LS: Filtek LS, AS: Adper Scotchbond SE Plus) and resin composite (FLS: Filtek LS; FS: Filtek Supreme). The specimens were fixed in an hourglass-shaped silicone matrix and the other half of the specimen was restored. Hourglass shaped specimens $(n=12)$ were used as positive control to measure the cohesive strength of the resin composite (Filtek LS). Microtensile bond test was performed $(0.5 \mathrm{~mm} / \mathrm{min})$ and failure types were analyzed. Data were analyzed using two-way ANOVA, Tukey's and Dunnett's tests $(\alpha=0.05)$. Adhesive protocol and resin composite significantly affected the results $(p<0.05)$. For the FS composite, the highest results were obtained using LS adhesive with $(18.4 \pm 7.7)$ and without $(18.8 \pm 4.8)$ bur roughening. For FLS composite, the highest results were obtained using AS adhesive with (33.2 \pm 7.1$)$ and without $(25.7 \pm 3.6)$ bur roughening. Without the use of adhesive resin, significantly lower bond strength results were observed with both LS $(5 \pm 2.1,4.5 \pm 1.5)$ and FLS $(2.2 \pm 1.2,4.4 \pm 1.1)$ for unground and diamond bur roughened groups, respectively $(p<0.0001)$. Cohesive strength of the FLS $(52.3 \pm 7.6)$ was significantly higher than any of the repaired groups $(p<0.0001)$. FS-LS combination and the groups repaired without adhesive presented more adhesive (Type I) failures.

Keywords: Adhesion, adhesive system, bond strength, resin composite, repair, silorane, surface conditioning 


\section{Introduction}

Silorane resin composites were introduced with the aim of reducing the polymerization shrinkage and decrease the shortcomings of methacrylate resin-based materials used for restorative procedures in dentistry [1]. The polymerization mechanism of silorane resin composites is based on photocationic ring opening being different than radical reaction present in methacrylate materials. Photocationic ring opening decreases polymerization shrinkage to almost $1 \%$ being significantly lower than methacrylate composites (4\%) [2].

Resin composite materials used in restorative dentistry offers the advantage of repair approach that prolongs the service life of failed restorations [3-7]. Repair procedures are considered minimal invasive and economic solutions in restorative dentistry since replacement of old restorations yield to removal of sound dental tissues surrounding of the restoration due to the difficulty to distinguish the restoration margins from the cavity walls $[8,9]$.

For durable repair, surface conditioning methods, adhesive systems and the compatibility of the substrate and repair composite are crucial factors to consider. However, limited information is available on the repair potential of low shrinkage silorane composite and its compatibility with the methacrylate-based resin composite [10-15]. Typically the history and type of substrate resin composite material is not known when the failed restoration has been made by another clinician. Although previous studies have evaluated the silorane repair [10-15], none of them investigated the influence of other adhesives different than the silorane specific adhesive in combination with different surface conditioning methods and resin composites.

The objectives of this study therefore were to evaluate the effect of the combination of surface conditioning methods, bonding agents, and resin composites on the repair bond strength of silorane and dimethacrylate based resin composites. The hypotheses tested were that a) the resin composite-adhesive resin combinations tested would not influence 
the repair bond strength and that $b$ ) the repair bond strength of resin composite would be similar to the cohesive strength of the silorane composite.

\section{Materials and Methods}

Specimen preparation

The types, brands, main chemical compositions, manufacturers and batch numbers of the materials used for the experiments are listed in Table 1.

Specimens $(\mathrm{N}=144)$ were prepared using low-shrinkage resin composite (FLS: Filtek LS, 3M ESPE, St. Paul, MN, USA, shade A2) with the help of silicone matrix that allowed a bonding area of $1 \mathrm{~mm}^{2}[16,17]$ (Fig. 1a). The specimens representing the restoration were prepared in an hourglass-shaped form so that the remaining half would serve for the repair (Figs. 1a-f).

The silicфne mould was filled with silorane resin composite, then covered with a Mylar strip and a microscope glass slab. In order to compress the material and prevent bubble formation, the glass was gently pressed and excess material was removed. The composite was polymerized for $40 \mathrm{~s}$, according to the manufacturer's recommendations, using a halogen photo-polymerization unit (Optilux 501, Sybron Kerr, Danbury, CT, USA) with light output of $650 \mathrm{~mW} / \mathrm{cm}^{2}$, that was monitored by a radiometer (model 100 , Demetron/Kerr, Danbury, CT, USA). The specimens were removed from the matrix and the area to be repaired was finished with abrasive discs (Soflex, 3M ESPE) to remove the oxygen-inhibited layer. The specimens were stored in distilled water at $37^{\circ} \mathrm{C}$ for $24 \mathrm{~h}$ $[3,15]$.

As positive control group, twelve hourglass-shaped specimens were prepared, to evaluate the cohesive strength of the silorane-based material, and compare the results 
with those of the groups repaired with different protocols. The half-hourglass-shaped specimens created were randomly distributed into twelve experimental groups $(n=12)$ according to the surface conditoning methods and adhesive protocol used, as described in Table 2.

Surface conditioning methods

The entire bonding surfaces of the specimens in Groups 8-10 were roughened with a diamond bur (No. \#3098, regular grit, KG Sorensen, Barueri, SP, Brazil) using a highspeed handpiece under constant water-cooling.

Specimens were repaired using a matrix with an hourglass-shape. The different adhesive protocols were performed on the confined area of the half-hourglass specimen in accordance with the manufacturer's instructions as follows:

Group LS: Primer was applied for 15 s, gently air-dried for 10 s and photo-polymerized for $10 \mathrm{~s}$. The adhesive resin (Filtek LS Bond, 3M ESPE) was then applied one coat and photo-polymerized for $10 \mathrm{~s}$.

Group AS: Primer was applied for 20 s, gently air-dried for $10 \mathrm{~s}$. The adhesive resin (Adper Scotchbond SE Plus, 3M ESPE) was then applied, gently air-dried and photopolymerized for $10 \mathrm{~s}$.

Group WA: In this group, no adhesive resin was used, acting as the control group.

After surface conditioning and/or adhesive resin application, the specimens were positioned in the mould and half of them were repaired with dimethacrylate based (FLS: Filtek LS) and the other half with silorane based resin composite (FS: Filtek Supreme, 3M ESPE).

Microtensile bond test

The adhesive interface area was measured using a digital caliper. The specimens were fixed to the microtensile device coupled to the Universal Testing Machine (EMIC, São José dos Pinhais, PR, Brazil), using a cyanoacrylate-based adhesive (Super Bonder gel, 
Loctite, São Paulo, SP, Brazil), in such way that the interface area was perpendicular to the long axis of the tensile force. The test was performed at a crosshead speed of 0.5 $\mathrm{mm} / \mathrm{min}$ until rupture of the interface. The microtensile bond strength values were obtained in kilogram-force (Kgf) and transformed into MPa $\left(\mathrm{N} / \mathrm{mm}^{2}\right)$.

Failure analysis

After the microtensile bond strength test, failure sites were evaluated using an optical microscope (x45, Meiji 2000, Meiji Techno, Saitama, Japan) and classified as follows: Type I: Adhesive failure at the interface; Type II: Mixed failure (a combination of more than one type of fracture); Type III: Cohesive failure in the substrate composite [3].

Statistical analysis

Data were analyzed using a statistical software package (SPSS Software V.20, Chicago, IL, USA). Kolmogorov-Smirnov and Shapiro-Wilk tests were used to test normal distribution of the data. As the data were normally distributed, 2-way analysis of variance (ANOVA) and Dunnett's tests were applied considering the factors of adhesive protocol (3 levels: LS, AS, WA) and resin composite (2 levels: FLS, FS). $P<0.05$ was considered to be statistically significant in all tests.

\section{Results}

Adhesive protocol and resin composite significantly affected the results $(p<0.05)$. Interaction terms were also significant $(p<0.0001)$.

For the FS composite, the highest mean repair bond strength results were obtained using LS adhesive, with $(18.4 \pm 7.7)$ and without $(18.8 \pm 4.8)$ roughening with bur (Table 3 ). On the contrary, for FLS composite, the highest mean repair bond strength results were

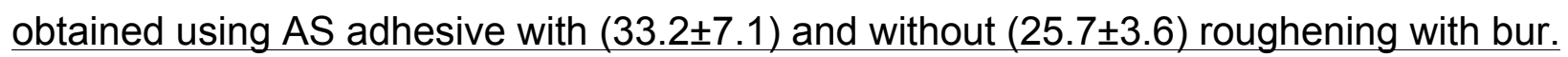


Without the use of adhesive resin significantly lower bond strength results were observed with both LS $(5 \pm 2.1,4.5 \pm 1.5)$ and FLS $(2.2 \pm 1.2,4.4 \pm 1.1)$ for unground and diamond bur roughened groups, respectively $(p<0.0001)$.

Cohesive strength of the FLS $(52.3 \pm 7.6)$ was significantly higher than any of the repaired groups (Dunnet Test, $p<0.0001$ ).

FS-LS combination and the groups repaired without the use of adhesive resin presented more incidences of adhesive (Type I) failures (Fig. 2). Other groups showed mainly mixed (Type II) failures.

\section{Discussion}

The present study evaluated the effect of adhesion systems and resin composites with different monomeric compositions on the repair bond strength of silorane based resin material. The results obtained indicated that the repair bond strength was affected with the adhesion protocol, yielding to rejection of the first hypothesis. Due to the significantly high cohesive strength of the silorane resin composite and that none of the adhesion protocols tested was capable to generate similar bond results after repair, the second hypothesis could also be rejected.

After the restorative procedures, due to trauma or fatigue, resin composites may present fractures. In this study, immediate repair situations were simulated. Thus, repair protocols were performed $24 \mathrm{~h}$ after the polymerization of the tested composite resins. Regarding the adhesive resins tested in combination with and without roughening, repair bond strength in FLS was compromised in combination with AS adhesive resin. The incompatibility between the systems is a possible explanation for these results. The adhesive AS is based on methacrylate monomers, being different to silorane resin composite that has the composition based on silorane monomer allowing for reduced shrinkage compared to the methacrylate systems [2]. The main component present in the 
hydrophobic

layer

FLS

composite

is

the

2,2-bis-(4-(3-

methacryloxypropoxy)phenyl)propane. Despite the methacrylate group, the epoxy group seems to be essential to obtain an optimal bond between the adhesive resin and silorane resin composite. Consequently, the incompatibility between the adhesive resin and resin composite did not yield to co-polymerization and resulted in lower repair bond results. The bond results were corroborated by the failure pattern observed in these groups where high incidences of adhesive failures were observed, signifying weak methacrylatesilorane interface.

When LS adhesive resin was used, FLS composite had improved the repair bonding regardless of the surface roughening with the diamond bur. LS adhesive resin was also capable of promoting better repair strength when used in combination with FS resin composite which is methacrylate based. Since the main composition of LS adhesive resin is 2,2-bis-(4-(3-methacryloxypropoxy)phenyl)propane, it is compatible with the low shrinkage silorane resin evaluated. Apparently, the high concentrated component present in the bond agent of the silorane adhesive could promote adhesion to both silorane and methacrylate resins, possibly due to the methacrylate group present in the main compound of the adhesive resin [18].

The surface conditioning with diamond bur roughening promoted better results using AS adhesive but when LS was used, the bond strength of roughened and unground groups were not significantly different. LS adhesive resin is a self-etch adhesive system that presents a hydrophilic photo-polymerized primer. This characteristic can possibly explain the obtained results since the interlocking with the grounded surface was achieved mainly by an agent with significantly reduced mechanical properties compared to the hydrophobic agent of the same system [19]. Similar results were observed in a previous study using only the primer of LS compared to repairs using only the adhesive resin of this system [10]. On other hand, AS is a conventional two-steps self-etching adhesive 
resin and the interface is therefore based on a hydrophobic agent mixed with a low amount of the primer into the micro retentions promoted by the diamond bur. This approach evidently allowed for stronger intermediate layer, justifying the better results obtained for this protocol. These results corroborate the findings of previous studies that demonstrated that the combination of surface conditioning and the use of dimethacrylate adhesive resin can promote adhesion of resin composites to silorane substrate $[5,20,21]$.

The results of this study clearly indicated that the use of adhesive resin was crucial in order improve repair strength of the resin composites tested. The intermediate adhesive layer promotes wettability of the surface, increasing the chemical interaction and interlocking between the surfaces and thus, improving the bonding. Due to the high viscosity of the resins evaluated, the interaction between the new and pre-polymerized resin composite was less favorable, resulting in lower values of repair bond compared to the cohesive strength, where AS combined with FLS resin composite resulted in the lowest repair bond strength as a result of adhesive-composite incompatibility. Failure types supported the bond results in that exclusively adhesive failures were observed in the groups without the application of adhesive resin.

Despite high bond strength values obtained with most of the repair protocols, none of the procedures performed promoted similar values compared to that of the cohesive strength of the silorane composite (positive control). The results obtained corroborate previous studies demonstrating reduced repair bond strength compared to the cohesive strength of the silorane resin composite [21,22].

The present study evaluated the effect of combination of resin composite, adhesive system, and surface conditioning on the repair bond strength of silorane composite, differing from previous studies $[10,15,18,23,24]$. The results demonstrated that the combination of surface conditioning with a bur, followed by application of methacrylatebased adhesive resin could be advised for the repair of silorane resin composite. 
Previous studies for the repair of resin composites employed air-particle abrasion protocols followed by silanization and adhesive resin application [25-29]. In fact, chairside particle abrasion devices add to the costs of the armamentarium. Thus, surface roughening with diamond bur and using adhesive resins would make the repair applications more cost effective, however their clinical reliability needs to be verified.

\section{Conclusions}

From this study, the following could be concluded:

1. The best repair protocol for the silorane composite was using diamond bur followed by the application of dimethacrylate based adhesive and resin composite.

2. The use of the self-etching methacrylate-based adhesive promoted repair bond strength for silorane composite.

3. Surface roughening with diamond bur was effective to improve the repair bond strength when Adper Scotchbond SE Plus dimethacrylate adhesive resin was used but no additional effect was observed for Filtek LS adhesive resin.

4. None of the adhesion protocols promoted repair bond to the level of cohesive strength of the silorane material.

\section{Clinical Relevance}

When repair is required for silorane composite restorations, roughening the surface to be repaired with diamond bur and subsequent application of two-step self-etch dimethacrylate adhesive resin (Adper Scotchbond SE Plus) with methacrylate based resin composite could be advised. 


\section{Acknowledgement}

The authors acknowledge 3M ESPE, St. Paul, MN, USA for providing the silorane system used in this study.

\section{Conflict of interest}

The authors did not have any commercial interest in any of the materials used in this study.

\section{References}

[1] Schmidt M, Kirkevang LL, Horsted-Bindslev P, Poulsen S. Marginal adaptation of a low-shrinkage silorane-based composite: 1-year randomized clinical trial. Clin Oral Investig 2011;15:291-295.

[2] Weinmann W, Thalacker C, Guggenberger R. Siloranes in dental composites. Dent Mater 2005;21:68-74.

[3] Cavalcanti AN, de Lima AF, Peris AR, Mitsui FH, Marchi GM. Effect of surface treatments and bonding agents on the bond strength of repaired composites. $\mathrm{J}$ Esthet Restor Dent 2007;19:90-98.

[4] Özcan M, Barbosa SH, Melo RM, Galhano GA, Bottino MA. Effect of surface conditioning methods on the microtensile bond strength of resin composite to composite after aging conditions. Dent Mater 2007;23:1276-1282.

[5] Wiegand A, Stawarczyk B, Buchalla W, Tauböck TT, Özcan M, Attin T. Repair of silorane composite-Using the same substrate or a methacrylate-based composite? Dent Mater. 2012;28:E19-E25.

[6] Hickel R., Brushaver K, Ilie N. Repair of restorations--criteria for decision making and clinical recommendations. Dent Mater 2013;29:28-50. 
[7] Özcan M, Corazza PH, Marocho SM, Barbosa SH, Bottino MA. Repair bond strength of microhybrid, nanohybrid and nanofilled resin composites: effect of substrate resin type, surface conditioning and ageing. Clin Oral Investig 2013;17:1751-1758.

[8] Krejci I, Lieber CM, Lutz F. Time required to remove totally bonded tooth-colored posterior restorations and related tooth substance loss. Dent Mater 1995;11:34-40.

[9] Gordan VV, Mondragon E, Shen C. Replacement of resin-based composite: evaluation of cavity design, cavity depth, and shade matching. Quintessence Int 2002;33:273-278.

[10] Luhrs AK, Gormann B, Jacker-Guhr S, Geurtsen W. Repairability of dental siloranes in vitro. Dent Mater. 2011;27:144-149.

[11] Giachetti L, Scaminaci Russo D, Baldini M, Goracci C, Ferrari M. Reparability of aged silorane with methacrylate-based resin composite: micro-shear bond strength and scanning electron microscopy evaluation. Oper Dent 2012;37:28-36.

[12] Popoff DA, Santa Rosa TT, Ferreira RC, Magalhães CS, Moreira AN, Mjör IA. Repair of dimethacrylate-based composite restorations by a silorane-based composite: a oneyear randomized clinical trial. Oper Dent 2012;37:E1-E10.

[13] Wiegand A, Stawarczyk B, Buchalla W, et al. Repair of silorane composite--using the same substrate or a methacrylate-based composite? Dent Mater 2012;28:e19-25.

[14] Baur V, llie N. Repair of dental resin-based composites. Clin Oral Investig 2013;17:601-608.

[15] Mobarak E, El-Deeb H. Two-year interfacial bond durability and nanoleakage of repaired silorane-based resin composite. Oper Dent 2013;38:408-418.

[16] Fawzy AS, El-Askary FS, Amer MA. Effect of surface treatments on the tensile bond strength of repaired water-aged anterior restorative micro-fine hybrid resin composite. $\mathrm{J}$ Dent 2008;36:969-976. 
[17] El-Askary FS, Fawzy AS, Abd Elmohsen HM. Tensile bond strength of immediately repaired anterior microfine hybrid restorative composite using nontrimmed hourglass specimens. J Adhes Dent 2009;11:41-47.

[18] Maneenut C, Sakoolnamarka R, Tyas MJ. The repair potential of resin composite materials. Dent Mater 2011;27:e20-7.

[19] Gaglianone LA, Lima AF, Goncalves LS, Cavalcanti AN, Aguiar FH, Marchi GM. Mechanical properties and degree of conversion of etch-and-rinse and self-etch adhesive systems cured by QTH and LED. J Mech Behav Biomed Mater 2012;12:139-143

[20] Lima AF, Ferreira SF, Catelan A, Palialol AR, Gonçalves LS, Aguiar FH, Marchi GM. The effect of surface treatment and bonding procedures on the bond strength of silorane composite repair. Acta Odontol Scand 2014;72:71-75.

[21] Spyrou M, Koliniotou-Koumpia E, Kouros P, Koulaouzidou E, Dionysopoulos P. The reparability of contemporary composite resins. Eur J Dent 2014;8:353-359.

[22] Kaneko M, Caldas RA, Feitosa VP, Xediek Consani RL, Schneider LF, Bacchi A. Influence of surface treatments to repair recent fillings of silorane-and methacrylatebased composites. J Conserv Dent 2015;18:242-246.

[23] Ivanovas $S$, Hickel $R$, llie $N$. How to repair fillings made by silorane-based composites. Clin Oral Investig 2011;15:915-922.

[24] Staxrud F, Dahl E. Role of bonding agents in the repair of composite resin restorations. Eur J Oral Sci 2011;119:316-322.

[25] Brendeke J, Özcan M. Effect of physicochemical aging conditions on the compositecomposite repair bond strength. J Adhes Dent 2007;9:399-406.

[26] Özcan M, Cura C, Brendeke J. Effect of aging conditions on the repair bond strength of a microhybrid and a nanohybrid resin composite. J Adhes Dent 2010;12:451-459. 
[27] Rinastiti M, Özcan M, Siswomihardjo W, Busscher HJ. Immediate repair bond strengths of microhybrid, nanohybrid and nanofilled composites after different surface treatments. J Dent 2010;38:29-38.

[28] Rinastiti M, Özcan M, Siswomihardjo W, , Busscher HJ. Effects of surface conditioning on repair bond strengths of non-aged and aged microhybrid, nanohybrid, and nanofilled composite resins. Clin Oral Investig 2011;15:625-633.

[29] Özcan M, Pekkan G. Effect of different adhesion strategies on bond strength of resin composite to composite-dentin complex. Oper Dent 2013;38:63-72. 


\section{Captions to figures and tales:}

\section{Tables:}

Table 1 The brands, types, manufacturers and chemical compositions of the main materials used in this study. bis-GMA: bisphenol-A glycidyldimethacrylate; HEMA: 2hydroxyethylmethacrylate; $\quad \mathrm{CQ}$ : camphorquinone; EDMAB: ethyl4dimethylaminobenzoate; DHEPT: dihydroxyethyl p-toluidine; UDMA: diurethane dimethacrylate; TEGDMA: triethylene glycol dimethacrylate; TMPTMA: trimethylolpropane triimethacrylate; bis-EMA6: bisphenol A polyethylene glycol diether dimethacrilate.

Table 2 Experimental and control groups according to the adhesive protocol and resin material used. FLS: Filtek LS Bond; FS: Filtek Supreme; LS: Filtek LS Bond; AS: Adper Scotchbond SE Plus; WA: Without adhesive.

Table 3 Means (Standard Deviation) of the repair bond strength of resin composites after various adhesion protocols. Different capital letters indicate statistical significant difference within each row, different lowercase letters indicate significant differences within each column. *Statistical difference between the experimental groups and positive control (Dunnet's Test; $\alpha=0.05$ ). See Table 2 for group abbreviations.

\section{Figures:}

Figs. 1a-f The schematic representation of the specimens prepared in an hourglassshape that received either no surface conditioning or surface roughening with a diamond bur.

Fig. 2 Distribution of failure types per group. Type I: Adhesive failure at the interface; Type 2: Mixed failure (a combination of more than one type of fracture); Type III: Cohesive failure in the substrate composite. See Table 2 for group descriptions. 
Tables:

\begin{tabular}{|c|c|c|c|}
\hline Brands & Type & Manufacturer & Chemical Composition \\
\hline Filtek LS & Resin composite & $\begin{array}{c}\text { 3M ESPE, St. Paul, } \\
\text { MN, USA }\end{array}$ & $\begin{array}{c}\text { Silane treated quartz, } \\
\text { 3,4epoxycyclohexylcyclopolymethylsiloxan } \\
\text { e; bis-3,4 epoxycyclohexylethylphenyl- } \\
\text { methylsilane, Yttrium Trifuoride }\end{array}$ \\
\hline Filtek Supreme & Resin composite & 3M ESPE & $\begin{array}{c}\text { Silane treated ceramic, silane treated } \\
\text { silica, UDMA, bis-GMA, TEGDMA, } \\
\text { EDMAB, CQ, BisEMA6 }\end{array}$ \\
\hline $\begin{array}{l}\text { Filtek LS } \\
\text { Adhesive System } \\
\text { P90 PRIMER }\end{array}$ & $\begin{array}{c}\text { Two-step, } \\
\text { self-etch adhesive }\end{array}$ & 3M ESPE & $\begin{array}{c}\text { Bis-GMA, HEMA, water, ethanol, silane } \\
\text { treated silica filler, CQ, phosphoric acid- } \\
\text { methacryloxy-hexylesters mixture, } \\
\text { phosphorylated methacrylates, copolymer } \\
\text { of acrylic and itaconic acid, phosphine } \\
\text { oxide }\end{array}$ \\
\hline $\begin{array}{l}\text { Filtek LS } \\
\text { Adhesive system } \\
\text { P90 BOND }\end{array}$ & & & $\begin{array}{l}\text { 2,2-bis-(4-(3- } \\
\text { methacryloxypropoxy)phenyl)propane, } \\
\text { phosphorylated methacrylates, TEGDMA, } \\
\text { silane treated silica, CQ, stabilizers }\end{array}$ \\
\hline $\begin{array}{l}\text { Adper } \\
\text { Scotchbond SE } \\
\text { Plus }\end{array}$ & $\begin{array}{c}\text { Two-step, } \\
\text { self-etch adhesive }\end{array}$ & 3M ESPE & $\begin{array}{c}\text { PRIMER: Water and HEMA. } \\
\text { BOND: TEGDMA, HEMA, EDMAB, CQ, } \\
\text { UDMA, TMPTMA, Di-HEMA } \\
\text { PHOSPHATES, }\end{array}$ \\
\hline
\end{tabular}

Table 1 The brands, types, manufacturers and chemical compositions of the main materials used in this study. bisGMA: bisphenol-A glycidyldimethacrylate; HEMA: 2-hydroxyethylmethacrylate; CQ: camphorquinone; EDMAB: ethyl4dimethylaminobenzoate; DHEPT: dihydroxyethyl p-toluidine; UDMA: diurethane dimethacrylate; TEGDMA: triethylene glycol dimethacrylate; TMPTMA: trimethylolpropane triimethacrylate; bis-EMA6: bisphenol A polyethylene glycol diether dimethacrilate. 


\begin{tabular}{cccc} 
Groups & Surface Conditioning & Adhesive System & Resin of repair \\
\hline 1 & --- & WA & FLS \\
2 & Unground & WA & FLS \\
3 & Unground & WA & FS \\
4 & Unground & LS & FLS \\
5 & Unground & LS & FS \\
6 & Unground & AS & FLS \\
7 & Unground & AS & FS \\
8 & Diamond Bur & WA & FLS \\
9 & Diamond Bur & WA & FS \\
10 & Diamond Bur & LS & FLS \\
11 & Diamond Bur & LS & FS \\
12 & Diamond Bur & AS & FLS \\
13 & Diamond Bur & AS & FS \\
\hline
\end{tabular}

Table 2 Experimental and control groups according to the adhesive protocol and resin material used. FLS: Filtek LS Bond; FS: Filtek Supreme; LS: Filtek LS Bond; AS: Adper Scotchbond SE Plus; WA: Without adhesive.

\begin{tabular}{ccc}
\hline & \multicolumn{2}{c}{ Resin Composite } \\
\cline { 2 - 3 } & \multicolumn{1}{c}{ FS } & FLS \\
\hline Unground-LS & $18.8(4.8) \mathrm{Aa}$ & $22.9(4.6) \mathrm{Ab}$ \\
Unground-AS & $8.0(3.0) \mathrm{Bbc}$ & $25.7(3.6) \mathrm{Aab}$ \\
Unground-WA & $5.0(2.1) \mathrm{Ac}$ & $2.2(1.2) \mathrm{Ac}$ \\
Diamond Bur-LS & $18.4(7.7) \mathrm{Aa}$ & $22.5(7.0) \mathrm{Ab}$ \\
Diamond Bur-AS & $11.0(2.2) \mathrm{Bb}$ & $33.2(7.1) \mathrm{Aa}$ \\
Diamond Bur-WA & $4.5(1.5) \mathrm{Ac}$ & $4.4(1.1) \mathrm{Ac}$ \\
\hline
\end{tabular}


Table 3 Means (Standard Deviation) of the repair bond strength of resin composites after various adhesion protocols. Different capital letters indicate statistical significant difference within each row, different lowercase letters indicate significant differences within each column. *Statistical difference between the experimental groups and positive control (Dunnet's Test; $\alpha=0.05$ ). See Table 2 for group abbreviations.

\section{Figures:}

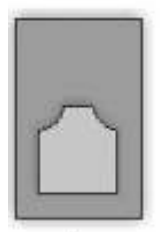

A

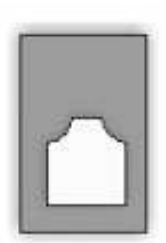

B

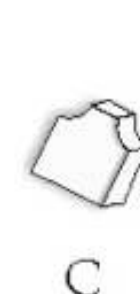

C

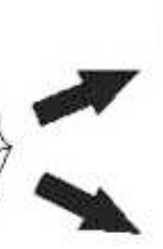

No surface conditioning

Diamond bur roughening

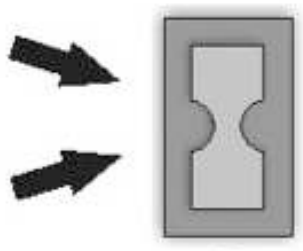

D

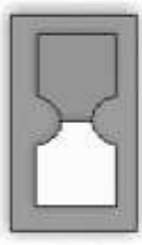

E

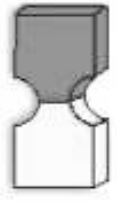

F

Figs. 1a-f The schematic representation of the specimens prepared in an hourglass-shape that received either no surface conditioning or surface roughening with a diamond bur.

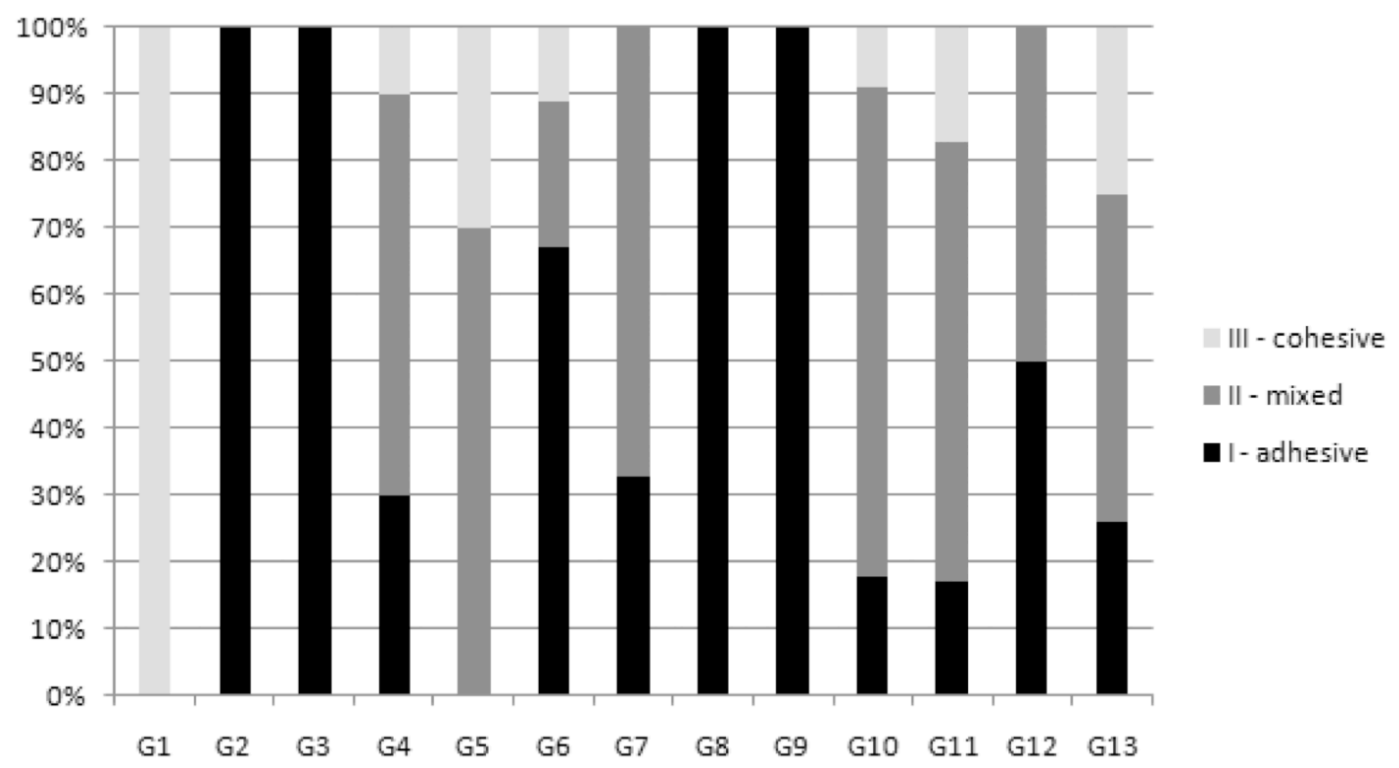

Fig. 2 Distribution of failure types per group. Type I: Adhesive failure at the interface; Type 2: Mixed failure (a combination of more than one type of fracture); Type III: Cohesive failure in the substrate composite. See Table 2 for group descriptions. 